\title{
Right atrial mass in a 23-year-old woman with molar pregnancy
}

\author{
Abhinav Sharma MD, Robinder S. Sidhu MD, D. Ian Paterson MD
}

Competing interests:

None declared.

This article has been peer reviewed.

The authors have obtained patient consent.

Correspondence to:

D. Ian Paterson,

ip3@ualberta.ca

CMAJ 2015.DOI:10.1503

/cmaj.140889

A 23-year-old woman underwent treatment for a molar pregnancy. She received five cycles of methotrexate and actinomycin D through a peripherally inserted central catheter (PICC). During treatment, a thrombus of the left basilic vein developed that necessitated removal of the PICC. Dalteparin was started. Subsequently, a right basilic vein PICC was inserted to complete chemotherapy. The patient initially had an adequate response: her $\beta$ human chorionic gonadotropin ( $\beta \mathrm{HCG}$ ) level returned to normal. However, two weeks after completing chemotherapy, the patient had acute vaginal bleeding, and her $\beta$ HCG rose to 475 (normal < 5) U/L. Computed tomography confirmed reoccurrence of malignant disease, and chemotherapy was restarted with cisplatin and high-dose methotrexate.

The patient presented to the emergency department one month later with acute dyspnea and vaginal bleeding. She had sinus tachycardia (130 beats/min), her blood pressure was $114 / 55 \mathrm{~mm} \mathrm{Hg}$, and her respiratory rate was 30 breaths/min. In addition, she had a fever $\left(38.5^{\circ} \mathrm{C}\right)$. Laboratory investigations showed low hemoglobin (93 [normal 120-160] g/L), a platelet count of 34 (normal 140-450) $\times 10^{9}$ cells $/ \mathrm{L}$ and a leukocyte count of 4.5 (normal 4.0 $11.0) \times 10^{9}$ cells $/ \mathrm{L}$. A peripheral blood smear was unremarkable, and the result of a heparininduced thrombocytopenia assay was negative. The patient's $\beta$ HCG had increased to $40842 \mathrm{U} / \mathrm{L}$, and her heparin levels were undetectable. A chest radiograph showed a rightsided PICC with the tip in the right atrium but was otherwise unremarkable. Computed tomography of the thorax showed a right atrial mass at the level of the tricuspid valve. No lymph nodes or pulmonary emboli were identified, and the lung parenchyma was unremarkable. Deep vein thromboses were not identified on Doppler ultrasonography of the leg. Computed tomography of the patient's abdomen and pelvis showed a persistent uterine mass and enlargement of the iliac lymph nodes, suspicious for progressive disease. A transthoracic echocardiogram showed a large
$(3 \times 3 \times 2.5 \mathrm{~cm})$ mobile mass attached to the right atrial free wall with involvement of the anterior tricuspid valve leaflet and intermittent obstruction of the valve orifice.

\section{What is the most likely diagnosis of the right atrial mass?}

a. Primary cardiac tumour

b. Metastatic disease from the gestational trophoblastic neoplasm

c. Infective endocarditis

d. Thrombus

e. Anatomic variant

Metastatic disease (b) was strongly considered owing to the failure of the initial chemotherapy, enlargement of the uterine growth and pelvic lymphadenopathy. However, a thrombus (d) was also possible, given the presence of the PICC in the right atrium, the history of basilic vein thrombosis and the undetectable heparin levels. Infective endocarditis (c) was less likely owing to the size of the mass but still considered because of the valvular involvement and the patient's fever. Primary cardiac tumours (a) are uncommon, and isolated right atrial involvement even more so. Right atrial anatomic variants (e), such as Eustachian valves and Chiari networks, are typically curvilinear structures adjacent to the inferior vena cava (Box 1). ${ }^{1-6}$

The patient was admitted to the cardiology ward, and treatment with aggressive fluid resuscitation was started. Cardiac magnetic resonance (CMR) imaging showed that the mass was isointense with myocardium on $T_{1}$ imaging, but there was no contrast uptake. In addition, we saw no adjacent tissue infiltration, and no intralesion hemorrhage (Figure 1). Overall, the CMR results were consistent with thrombus (Box 2), ${ }^{2,3}$ prompting anticoagulation therapy to be restarted. Owing to inadequate anticoagulation with dalteparin before admission, unfractionated heparin was administered intravenously. The patient was given broad spectrum antibiotics and growth colony 
stimulating factor, but she remained febrile and tachycardic. Initial blood and urine cultures showed no growth; however, on day three, the patient's neutrophil count decreased to 0.3 (normal $1.8-7.5) \times 10^{9}$ cells $/ \mathrm{L}$, and her leukocyte count decreased to $1.9 \times 10^{9}$ cells $/ \mathrm{L}$.

\section{How would you confirm the diagnosis?}

a. Repeat imaging after empiric treatment

b. Transvenous biopsy of cardiac mass

c. Transbronchial biopsy

d. Surgical excision of the mass

e. Positron emission tomography with fludeoxyglucose

Owing to ongoing diagnostic uncertainty and the lack of clinical improvement in the patient, we did a transvenous biopsy (b). The mass was readily accessible using an ultrasonography-guided, transvenous approach because of its location in the right atrium. Serial imaging with CMR after empiric treatment with anticoagulant and antibiotic agents (a) was considered; however, the possibility of metastatic disease required a rapid and definitive diagnosis to direct appropriate treatment. A transbronchial biopsy (c) would not have allowed access to the right atrial mass, and surgical excision (d) was unnecessary given the relative ease in obtaining a transvenous biopsy. Positron emission tomography with fludeoxyglucose (e) would not have provided information additional to that obtained by transthoracic echocardiography and CMR.

The biopsy showed fibrous tissue consistent with a thrombus. Antibiotic therapy was subsequently stopped after persistently negative blood cultures and return of the patient's neutrophil count to normal.

\section{How would you manage this large atrial thrombus?}
a. Fibrinolytic therapy through PICC line
b. Removal of PICC line and prolonged intra- venous administration of heparin
c. Surgical excision
d. Inferior vena cava filter insertion
e. Urgent hysterectomy

\begin{tabular}{|c|c|c|}
\hline Atrial mass & Prevalence & Location \\
\hline Primary cardiac tumour & $\begin{array}{l}\text { Benign: } 75 \%-90 \% \\
\text { Myxomas: } 30 \% \\
\text { Papillary fibroelastomas: } 10 \% \\
\text { Lipoma: } 10 \% \\
\text { Malignant: } 10 \%-25 \% \\
\text { Sarcomas: } 95 \% \\
\text { Lymphoma: } 5 \%\end{array}$ & $\begin{array}{l}\text { Myxoma } \\
\text { Left atrium: } 75 \% \\
\text { Right atrium: } 20 \% \\
\text { Sarcoma } \\
\quad \text { Atria > ventricles }\end{array}$ \\
\hline Metastatic tumour & $\begin{array}{l}\text { Lung: } 30 \%-39 \% \\
\text { Breast: } 10 \%-12 \% \\
\text { Hematologic: } 10 \%-21 \%\end{array}$ & Any chamber \\
\hline Thrombus & $\begin{array}{l}\text { Left atrium } \\
\text { Nonvalvular AF } \\
\text { Precardioversion: } 1 \%-10 \% \\
\text { Postembolic: } 15 \%-25 \% \\
\text { Valvular AF } \\
\text { Perioperative: } 5 \%-15 \% \\
\text { Right atrium } \\
\text { Central line: } 5 \% \\
\text { Nonvalvular AF: < } 1 \%\end{array}$ & $\begin{array}{l}\text { Nonvalvular AF } \\
\quad \text { Left atrial appendage: } 89 \% \\
\text { Left atrial cavity: } 11 \% \\
\text { Valvular AF } \\
\quad \text { Left atrial appendage: } 56 \% \\
\text { Left atrial cavity: } 44 \%\end{array}$ \\
\hline Pseudotumour & $\begin{array}{l}\text { Lipomatous hypertrophy of } \\
\text { the interatrial septum } \\
\text { Anatomical structure } \\
\text { Vegetation } \\
\text { Pericardial cyst }\end{array}$ & $\begin{array}{l}\text { Anatomical structure } \\
\text { Right atrium } \\
\text { Eustachian valve } \\
\text { Chiari network } \\
\text { Left atrium } \\
\text { Coumadin ridge } \\
\text { Vegetation } \\
\text { Valves }>\text { cavity }\end{array}$ \\
\hline
\end{tabular}


The patient was switched to unfractionated heparin administered intravenously, and the PICC was removed (b). Because our patient did not have hemodynamic instability associated with a pulmonary embolism, fibrinolytic therapy (a) was not required. Surgical excision (c) should

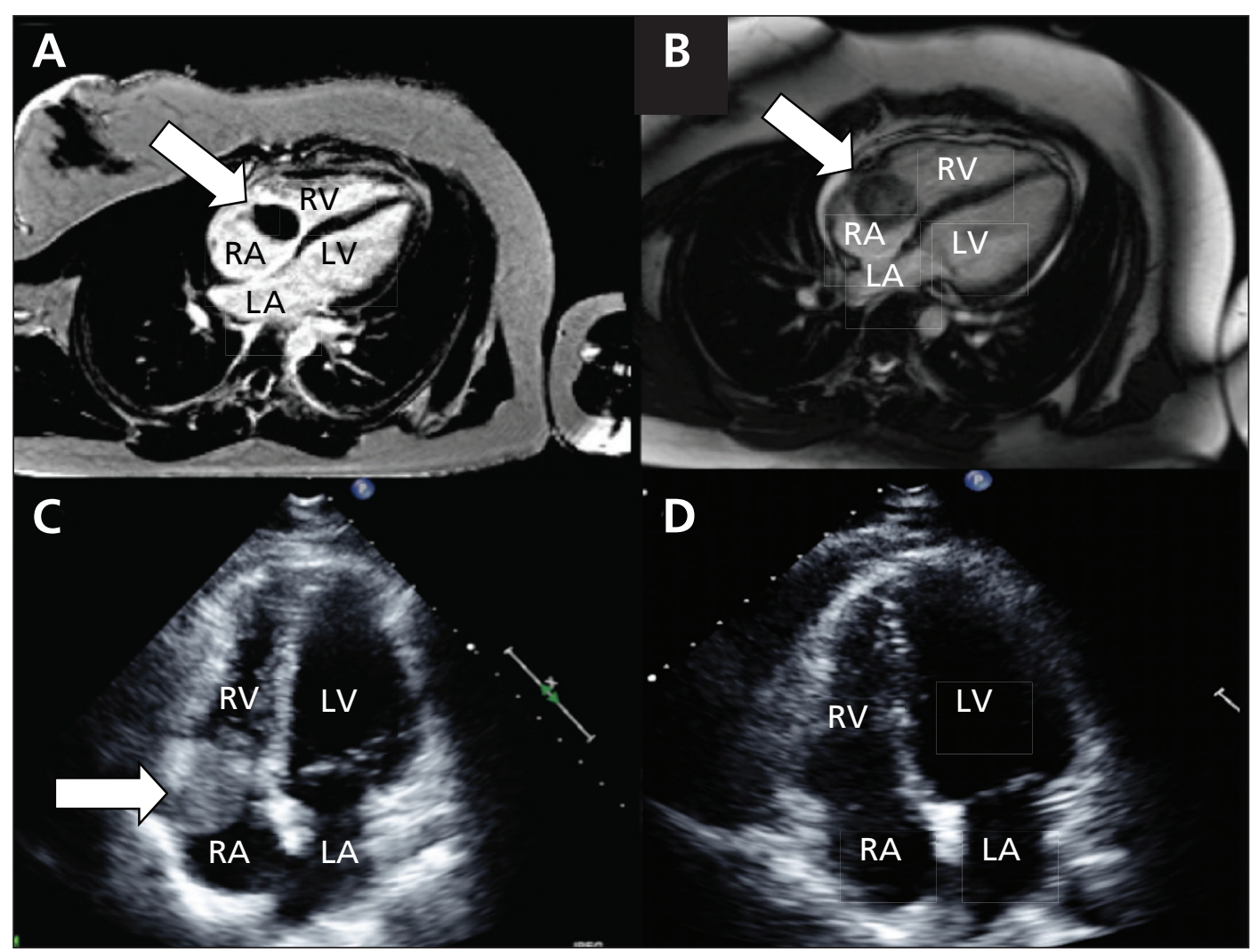

Figure 1: (A) Cardiac magnetic resonance imaging showing right atrial mass (white arrow) in a 23-year-old woman. The absence of contrast uptake on late gadolinium enhancement suggests a lack of vascularity. (B) Cardiac magnetic resonance steady-state free precession imaging showing the location of the mass (white arrow) and lack of myocardial infiltration. (C) Transthoracic echocardiography showing a right atrial mass prolapsing (white arrow) into the right ventricle. (D) The mass is no longer visible 1 month after treatment with heparin. Note: LA = left atrium, LV = left ventricle, RA = right atrium, RV = right ventricle.

Box 2: Comparison of cardiac mass features on transthoracic echocardiography and cardiac magnetic resonance imaging ${ }^{2,3}$

\begin{tabular}{|c|c|c|c|c|}
\hline $\begin{array}{l}\text { Imaging } \\
\text { modality }\end{array}$ & Thrombus & Benign tumour & $\begin{array}{c}\text { Primary malignant } \\
\text { tumour }\end{array}$ & Metastatic tumour \\
\hline $\begin{array}{l}\text { Transthoracic } \\
\text { echocardiography }\end{array}$ & $\begin{array}{l}\text { - Associated with severe } \\
\text { left ventricular } \\
\text { dysfunction, atrial } \\
\text { fibrillation and mitral } \\
\text { valve disease }\end{array}$ & $\begin{array}{l}\text { - Mobile } \\
\text { - Connected to the } \\
\text { interatrial septum with a } \\
\text { stalk (especially with } \\
\text { myxomas) } \\
\text { - Homogenous and } \\
\text { hyperechoic (e.g. } \\
\text { lipomas) }\end{array}$ & $\begin{array}{l}\text { - Broad-based } \\
\text { - Invasion of the } \\
\text { myocardium and } \\
\text { inferior vena cava }\end{array}$ & $\begin{array}{l}\text { - Pericardial } \\
\text { involvement } \\
\text { - Pericardial effusion }\end{array}$ \\
\hline $\begin{array}{l}\text { Cardiac magnetic } \\
\text { resonance }\end{array}$ & $\begin{array}{l}\text { - Low signal intensity on } \\
T_{1} \text { - and } T_{2} \text {-weighted } \\
\text { imaging in chronic } \\
\text { thrombus } \\
\text { - No contrast uptake }\end{array}$ & $\begin{array}{l}\text {-Well-defined borders } \\
\text { - Homogeneous } \\
\text { - Small hemorrhages may } \\
\text { be seen within the mass }\end{array}$ & $\begin{array}{l}\text { - Ill defined with } \\
\text { irregular borders } \\
\text { - }>5 \mathrm{~cm} \\
\text { - Invasion of adjacent } \\
\text { tissue } \\
\text { - Intralesion hemorrhage } \\
\text { and necrosis } \\
\text { - Contrast enhancement } \\
\text { - Hemorrhagic } \\
\text { pericardial effusion }\end{array}$ & $\begin{array}{l}\text { - Similar to malignant } \\
\text { tumours } \\
\text { - Extra cardiac } \\
\text { involvement }\end{array}$ \\
\hline
\end{tabular}


be considered for a cardiac tumour; however, treatment with anticoagulants was more appropriate given the results of the biopsy. An inferior vena cava filter (d) was not required owing to absence of deep vein thrombosis. Hysterectomy (e) was needed to treat the uterine malignant growth but would not have addressed the intracardiac mass.

After one month of intravenous heparin administration, the patient was switched to enoxaparin sodium, and the mass resolved within six months (Figure 1D). The patient underwent a total abdominal hysterectomy after three months of receiving anticoagulation therapy, with resolution of the serum $\beta \mathrm{HCG}$. A hypercoagulability workup (including antithrombin, proteins $\mathrm{C}$ and $\mathrm{S}$, factor $\mathrm{V}$ Leiden, prothrombin gene mutation, lupus anticoagulant and anticardiolipin antibodies) was done during a six-month follow-up visit, the results of which were negative.

\section{Discussion}

Differentiating intracardiac tumours from thrombus and infectious vegetations is essential to direct appropriate treatment. Our patient's case highlights the difficulty in differentiating these entities in the context of malignant disease, febrile neutropenia and dyspnea.

The evaluation of an intracardiac mass is complex and often requires a multimodal approach. Transthoracic echocardiography is the first-line test to identify cardiac masses ${ }^{2}$ because it is readily available and elucidates the anatomic and physiologic effect of the mass. This approach can also delineate concurrent pericardial effusions, suggesting a malignant cause. Cardiac magnetic resonance imaging may be considered in the initial evaluation of cardiac tumours. ${ }^{3}$ Owing to its superior ability to evaluate different tissue types, CMR provides detailed information about the mass, cardiac function, pericardial disease and extracardiac involvement (e.g., lymph nodes). ${ }^{3}$ Computed tomography can also evaluate cardiac masses in addition to pulmonary embolism and extracardiac disease; however, cardiac function will not be well determined.

In our patient's case, transthoracic echocardiography identified the mass as noncalcified and homogeneous, and the presence of a PICC suggested thrombus. However, the valvular location of the mass was more in keeping with tumour or vegetation. Cardiac magnetic resonance imaging characterized the mass as nonhemorrhagic, nonnecrotic and devoid of contrast uptake, features more consistent with thrombus. Complicating matters was the failure of chemo- therapy to cure the gestational trophoblastic neoplasia. However, metastatic disease to the heart in such a case is exceedingly rare, with only a few reported cases. ${ }^{7}$

The prevalence of right atrial thrombus varies according to the clinical scenario, affecting less than $1 \%$ of patients with atrial fibrillation ${ }^{4}$ and $5 \%$ of those undergoing chemotherapy with a central venous catheter. ${ }^{5}$ Right atrial thrombi have been classified into three main types. Type A thrombi are typically "worm-like" and represent "thrombi-in-transit" from deep vein thrombosis. Type B thrombi are attached to the atrial wall and found in structurally abnormal atria or in the presence of foreign bodies, such as catheters. Type $\mathrm{C}$ thrombi have features of both types A and B. ${ }^{6}$ Our patient's case most likely represented a type B thrombus. Optimal treatment for type $\mathrm{B}$ is uncertain but involves catheter removal and subsequent reinsertion of another line once the patient has undergone anticoagulation therapy. ${ }^{8}$ Data from small observational studies suggest that thrombi larger than $6 \mathrm{~cm}$ in diameter should be considered for thrombectomy. ${ }^{6} \mathrm{~A}$ recommendation based on low-grade evidence proposes fibrinolytic therapy in the setting of rightsided thrombosed prosthetic heart valves. ${ }^{8}$ Evidence from small observational studies recommends considering fibrinolytic therapy in the setting of catheter-related thrombi with pulmonary embolism. ${ }^{9}$ However, our patient did not fit these clinical profiles. Given the high risk of bleeding with the uterine malignant growth, fibrinolytic therapy was ruled out.

Several factors contributed to the thrombus formation in our patient's heart. The presence of the PICC in the right atrium likely provided substrate for thrombus development. In addition, the patient's underlying malignant disease and elevated $\beta \mathrm{HCG}$ may have increased thrombogenicity. In another case of right atrial thrombus obstructing the tricuspid valve, administration of exogenous gonadotropin was identified as a contributing factor to hypercoagulability. ${ }^{10}$ The chemotherapeutic agent given to our patient, cisplatin, has also been shown to increase risk of thrombus development. ${ }^{11}$ Given these multiple risk factors, hypercoagulability testing was of limited value in our patient and would be better reserved for cases of unexplained thrombosis.

\section{References}

1. Werner JA, Cheitlin MD, Gross BW, et al. Echocardiographic appearance of the Chiari network: differentiation from right heart pathology. Circulation 1981;63:1104-9.

2. Ragland MM, Tak T. The role of echocardiography in diagnosing space-occupying lesions of the heart. Clin Med Res 2006;4: $22-32$.

3. Motwani M, Kidambi A, Herzog BA, et al. MR imaging of cardiac tumors and masses: a review of methods and clinical applications. Radiology 2013;268:26-43. 
4. Bashir M, Asher CR, Garcia MJ, et al. Right atrial spontaneous echo contrast and thrombi in atrial fibrillation: a transesophageal echocardiography study. J Am Soc Echocardiogr 2001;14: 122-7.

5. Meisenberg BR, Callaghan M, Sloan C, et al. Complications associated with central venous catheters used for the collection of peripheral blood progenitor cells to support high-dose chemotherapy and autologous stem cell rescue. Support Care Cancer 1997;5:223-7.

6. The European Cooperative Study on the clinical significance of right heart thrombi. European Working Group on Echocardiography. Eur Heart $J$ 1989;10:1046-59.

7. Bozaci EA, Taskin S, Gürkin O, et al. Intracavitary cardiac metastasis in pulmonary tumor emboli of choriocarcinoma: the first case diagnosed and treated without surgical intervention. Gynecol Oncol 2005;99:753-6.

8. Whitlock RP, Sun JC, Fremes SE, et al.; American College of Chest Physicians. Antithrombotic and thrombolytic therapy for valvular disease: antithrombotic therapy and prevention of thrombosis, 9th ed: American College of Chest Physicians Evidence-Based Clinical Practice Guidelines. Chest 2012; 141(2 Suppl):e576S-600S

9. Stavroulopoulos A, Aresti V, Zounis C. Right atrial thrombi complicating haemodialysis catheters. A meta-analysis of reported cases and a proposal of a management algorithm. Nephrol Dial Transplant 2012;27:2936-44.

10. Basarici I, Belgi A, Yalcinkaya S. Tricuspid valve thrombus: A case report associated with gonatropin-releasing hormone analogue therapy and review of the literature. Can J Cardiol 2008;24:401-3

11. Seng S, Liu Z, Chiu SK, et al. Risk of venous thromboembolism in patients with cancer treated with cisplatin: a systematic review and meta-analysis. J Clin Oncol 2012;30:4416-26.
Affiliations: Division of Cardiology, Mazankowski Alberta Heart Institute, University of Alberta, Edmonton, Alta.

Contributors: Ian Paterson and Abhinav Sharma contributed to the design of the manuscript. All of the authors contributed to the drafting and revision of the manuscript and to the collection of data, and approved the final version submitted for publication.

Acknowledgements: The authors thank Dr. Valerie Capstick and Dr. Jeffrey Patterson for their help in caring for this patient and in the preparation of this manuscript.

CMAJ invites submissions to "What is your call?" Clinical details (including images) are presented with a multiple-choice question about the diagnosis. The answer and a brief discussion of the condition follow. We specifically invite submissions illustrating common or important radiographic and electrocardiographic diagnoses of appeal to a general audience. We require authors to obtain consent from the patient for publication of his or her story (form available at www.cmaj.ca/site/authors /checklist.xhtml). Submit manuscripts online at http://mc.manuscriptcentral.com/cmaj. 